\title{
Rosai-Dorfman Disease Presenting as Bilateral Eyelid Swellings
}

\author{
Sanjay Jogai ${ }^{a}$ Labiba Temmim $^{\text {a }}$ Abdullah Al-Baghli $^{\text {b }}$ \\ Aaron Olaolu Adesina ${ }^{a}$ \\ ${ }^{a}$ Department of Histopathology, Hussain Makki Juma Centre for Specialised Surgeries, and \\ ${ }^{\mathrm{b}}$ Abdul Rahman Al-Bahar Eye Center, Kuwait
}

\section{Key Words}

Sinus histiocytosis with massive lymphadenopathy • Bilateral eyelid swellings $\cdot$ Lymphocytophagocytosis

\begin{abstract}
Objective: To report a case of sinus histiocytosis with massive lymphadenopathy (Rosai-Dorfman disease) in an extranodal site with unusual presentation. Case Presentation: A 19-year-old girl presented with bilateral upper eyelid swellings of 2 years duration due to tumor. The masses were excised and sent for histopathological examination. Microscopic examination revealed similar features in both masses in the form of a collection of large histiocytic cells showing emperipolesis (lymphocytophagocytosis). The histiocytic cells stained positively with S-100 protein and CD68. The background comprised small lymphocytes and plasma cells. Based on the overall features a diagnosis of sinus histiocytosis with massive lymphadenopathy or Rosai-Dorfman disease was made. Conclusion: The present case highlights one of the forms in which extranodal Rosai-Dorfman disease can manifest itself. It is important to keep this differential diagnosis in mind whenever such histopathological features are encountered.
\end{abstract}

Copyright (C) 2006 S. Karger AG, Basel

\section{Introduction}

Rosai-Dorfman disease, also known as sinus histiocytosis with massive lymphadenopathy (SHML), was first described in 1969 by Rosai and Dorfman [1]. Typically, it presents as bilateral, massive painless lymph node enlargement in the neck, usually in the first two decades of life, though involvement at all ages is known. Extranodal involvement is known to occur in nearly $28-43 \%$ of cases [2]. Usually this is accompanied by nodal involvement and hence the disease is easily recognized. However, in some cases extranodal manifestations represent the predominant or less commonly exclusive manifestation of the disease. We report a case of Rosai-Dorfman disease presenting as bilateral eyelid swellings.

\section{Case Report}

A 19-year-old girl presented with bilateral upper eyelid masses of about 2 years duration. The masses were slowly increasing in size. On ophthalmologic consultation, the left upper eyelid swelling measured about $2 \mathrm{~cm}$ in diameter whereas the right mass measured $1 \mathrm{~cm}$. Both were subcutaneous in location. A clinical diagnosis of sebaceous cysts was made. There were no other masses elsewhere in the body. The two tumors were excised and sent for histopathological examination.

The left eyelid swelling measured $2 \times 1 \times 0.8 \mathrm{~cm}$ and the right one measured $1 \times 0.8 \times 0.8 \mathrm{~cm}$. Both had a smooth outer surface and on slicing they were yellowish brown and homogenous in appearance. Both appeared to be lymphnodes.

\begin{tabular}{ll}
\hline KARGER & ( ) 2006 S. Karger AG, Basel \\
1011-7571/06/0152-0163\$23.50/0 \\
$\begin{array}{l}\text { Fax +4161306 } 1234 \\
\begin{array}{l}\text { E-Mail karger@karger.ch } \\
\text { www.karger.com }\end{array}\end{array}$ & $\begin{array}{l}\text { Accessible online at: } \\
\text { www.karger.com/mpp }\end{array}$
\end{tabular}

Dr. Sanjay Jogai

Specialist Registrar, Histopathology

Salisbury District Hospital

Salisbury SP2 8BJ (UK)

Tel. +44 7910218 987, Fax +44 1722341 499, E-Mail sanjayjogai@rediffmail.com 


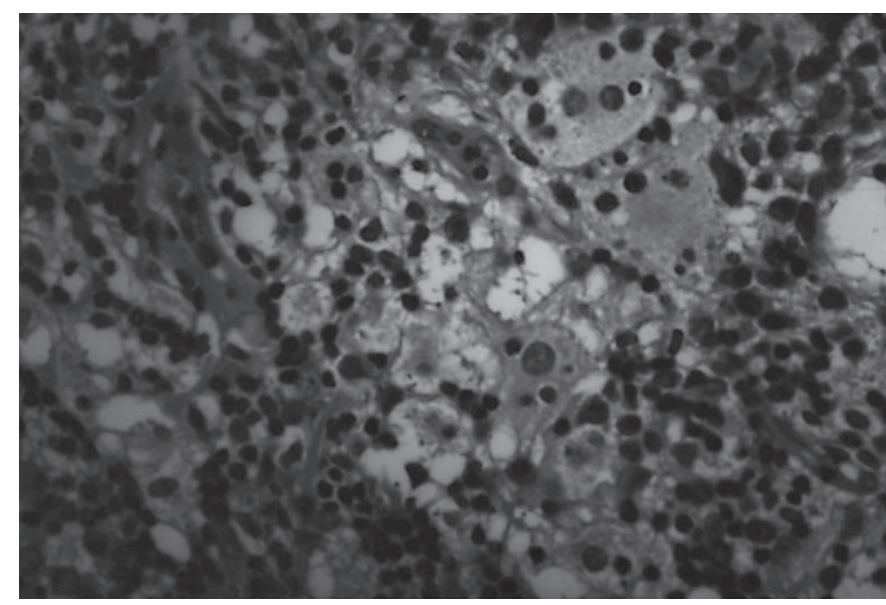

Fig. 1. Histiocytes showing lymphocytophagocytosis (emperipolesis) along with mixed lymphoplasmacytic infiltrate. HE. $\times 40$.

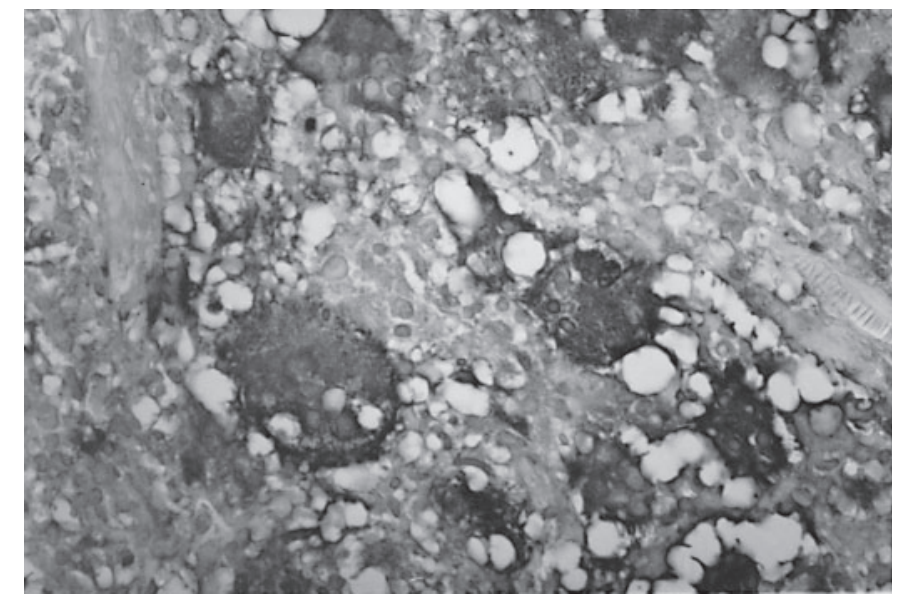

Fig. 2. Histiocytes showing immunopositivity with S-100 protein. Immunohistochemistry. $\times 40$.
Microscopic examination showed similar features in both masses. The lesion was relatively well circumscribed and on low magnification many pale staining areas were seen. On high power these areas were rich in large cells with fairly monotonous intermediate sized round nuclei with conspicuous nucleoli and abundant pale eosinophilic cytoplasm. Characteristically, these large cells showed phagocytosed lymphocytes and occasional plasma cells and polymorphs (emperipolesis/lymphocytophagocytosis) (fig. 1). These histiocytic aggregates alternated with collections of small lymphocytes and plasma cells. Rusell bodies were also seen. On immunohistochemistry, these cells stained positively with S-100 protein (fig. 2). In addition, these stained positively with macrophage marker CD68. Based on the overall features a diagnosis of extranodal SHML was made. The patient was re-examined for any nodal or other extranodal involvement but none was detected. No systemic abnormality was found.

\section{Discussion}

Rosai-Dorfman disease, also known as SHML, is a well described entity. Typical cases present with massive painless, bilateral lymph node enlargement in the neck usually occurring in the first two decades of life. In over $25 \%$ of cases, the disease involves extranodal sites [3]. Usually this occurs in the presence of nodal involvement, hence its easy clinical recognition. However, in many cases predominant or exclusive extranodal involvement is seen. The most common sites are eye and ocular adenexa [4] followed by head and neck region [5], upper respiratory tract [6] and skin [7].

The various ophthalmologic manifestations include proptosis, ptosis, conjuctival masses and uveitis. Most cases present with lymphoproliferation in the soft tissues of the orbit and eyelids. Our patient presented with isolated bilateral upper eyelid swellings. There was neither nodal involvement nor any systemic manifestation. A similar case, however, with involvement of all four eyelids has been reported previously [8]. Another case presented with relapsing uveitis and bilateral subconjunctival masses [2].

The present case showed the classical histopathological features of Rosai-Dorfman disease. The characteristic histiocytes showing emperipolesis (lymphocytophagocytosis) stained positively with S-100 protein on immunohistochemistry, thus confirming the histological diagnosis. The differential diagnosis that should be considered include Langerhans cell histiocytosis, which lacks emperipolesis and shows prominent nuclear grooves and folding. Langerhans cell histiocytosis cells are also CD1a positive and show Birbeck granules ultrastructurally. Nonspecific sinus hyperplasia may mimic Rosai-Dorfman disease; however, the histiocytes are S-100 negative and do not show emperipolesis. Metastatic malignant melanoma can be ruled out by appropriate immunostains (HMB45) and the lack of emperipolesis. Similarly, metastatic carcinoma shows positivity for epithelial markers.

Usually, Rosai-Dorfman disease undergoes quick and complete spontaneous resolution. In some, it follows a protracted clinical course for years or decades. It is relatively unaffected by therapy although chemotherapy has proved effective in some cases. 


\section{Conclusion}

The present case highlights one of the forms in which extranodal Rosai-Dorfman disease can manifest itself, as bilateral subcutaneous eyelid swellings. The charac- teristic histological and immunohistochemical findings prove to be of immense value in establishing the diagnosis, and one needs to be aware of this entity whenever such cases are subjected to histopathological examination.

\section{References}

1 Rosai J, Dorfman RF: Sinus histiocytosis with massive lymphadenopathy, newly recognized benign clinicopathological entity. Arch Pathol 1969;87:63-70.

-2 Tan HY, Kao LY: Rosai-Dorfman manifesting as relapsing uveitis and subconjunctival masses. Chang Gung Med J 2002;25:621-625.

-3 Foucar E, Rosai J, Dorfman RF: Sinus histiocytes with masive lymphadenopathy (RosaiDorfman disease). Review of the entity. Semin Diagn Pathol 1990; 7:19-73.
Foucar E, Rosai J, Dorfman RF: The opthalmologic manifestations of sinus histiocytosis with massive lymphadenopathy. Am J Ophthalmol 1979;87:354-367.

5 Wenig BN, Abbondanzo SL, Childers EL, Kapadia SB, Heffner DR: Extranodal sinus histiocytosis with massive lymphadenopathy (Rosai-Dorfman disease) of the head and neck. Hum Pathol 1993;24:483-492.
-6 Foucar E, Rosai J, Dorfman RF: Sinus histiocytosis with massive lymphadenopathy. Ear, nose and throat manifestations. Arch Otolaryngol 1978;104:687-693.

7 Thawerani H, Sanchez RL, Rosai J, Dorfman RF: The cutaneous manifestation of sinus histiocytosis with massive lymphadenopathy. Arch Dermatol 1978;114:191-197.

$>8$ Zimmerman LE, Hidayat AA, Grantham RL, et al: Atypical cases of sinus histiocytosis (Rosai-Dorfman disease) with ophthalmological manifestations. Trans Am Ophthalmol Soc 1988;86:113-135. 